\author{
QUERER Y CREER EN KIERKEGAARD \\ http://doi.org/10.54354/FCYN8050
}

\author{
Carmen Izco Esteban \\ Universidad de San Dámaso, Madrid
}

\begin{abstract}
Resumen
La postura de Kierkegaard respecto a la implicación de la libertad en el acto de fe será calificada en este escrito como volicionismo moderado. Este defiende la posibilidad lógica y psicológica de la fe como elección. De esta forma pretendemos aclarar y desarrollar la propuesta del autor danés en lo que respecta a la fe como acto libre que abraza la paradoja del misterio.
\end{abstract}

Palabras clave: Querer, creer, fe, libertad, cristianismo.

\begin{abstract}
Kierkegaard's position regarding the implication of freedom in the act of faith will be qualified in this writing as moderate volitionism. It defends the logical and psychological possibility of faith as a choice. In this way we intend to clarify and develop the Danish author's proposal regarding faith as a free act that embraces the paradox of mystery.
\end{abstract}

Keywords: Will, believe, faith, freedom, Christianity.

El objetivo que nos proponemos es mostrar que la fe en Kierkegaard como acto libre del espíritu, no implica atribuir irracionalidad ni a este, ni a su contenido, tal y como se le atribuye por parte de Pojman ${ }^{1}$. En este sentido denominaremos volicionismo ${ }^{2}$ moderado a la postura que defiende

Recibido el 12 de abril de 2021; aceptado el 22 de mayo de 2021.

1 Louis P. Pojman, Religious belief and the will, Londres \& Nueva York: Roulade \& Kegan Paul, 1986, p.74: "I have criticized the anti-racional element in some parts of his concept [sobre la fe]. He seems to have too narrow a notion of reason, not realizing that intuition and testimony are forms of evidencia which may be taken into the picture when assessing the merits of a proposition" p.74.

2 Aunque es cierto que el origen de este término se encuentra en el de volición, como acto de la 'voluntad' -entendida como facultad-, no pretendemos con ello sustentar un modelo antropológico basado en facultades, porque no sería congruente con el pensamiento de Kierkegaard. El volicionismo es un término acuñado por Pojman en la 
Kierkegaard. Frente a la posición del racionalismo, que afirma que el acto de fe es una mera conclusión a un razonamiento lógico o a una evidencia objetiva que nos arrastra a dicha aceptación de forma necesaria, y frente a la postura fideísta, que sostiene que dicho salto no se apoya en ninguna evidencia; el volicionismo moderado de Kierkegaard y otros autores ${ }^{3}$, defiende la posibilidad lógica y psicológica de dicho salto. Finalmente, frente al volicionismo extremo de Descartes, que admite la legitimidad de decidir creer en cualquier caso, Kierkegaard defiende su posibilidad sólo en algunos $^{4}$, entre los cuales está la fe religiosa, de la que nos ocuparemos en este escrito.

Los textos centrales que vamos a abordar son Migajas y el Postscriptum, porque son las obras en las que de forma explícita rompe los esquemas racionalistas sobre la fe religiosa. También acudiremos a $O$ lo uno o lo otro, por la importancia que reviste respecto al tema de la elección; a El concepto de la angustia, ya que el pecado es un momento fundamental en la dialéctica que nos conduce a la fe; y a Temor y temblor, para investigar el impacto existencial que recibe el que se acerca a la paradoja de la fe. Finalmente, vemos fundamental el análisis de las obras donde mejor nos parece expresa el autor su visión del cristianismo: Los lirios del campo y las aves del cielo, así como Ejercitación del cristianismo. A esta última acudiremos siempre que algún dato sobre la fe religiosa deba ser aclarado.

La metodología que seguiremos será, en primer lugar, aclarar el concepto de lo absurdo, tal y como lo explicita el autor, para descartar toda interpretación irracionalista de este y poder comprender adecuadamente el concepto de lo paradójico. Una vez hecha esta distinción, comenzaremos por analizar los diferentes significados que presenta el acto de creer en Kierkegaard, para situar de forma apropiada el concepto kierkegaardiano de fe. La fe como modo de acceso a la realidad de Dios es un acto libre de la

obra anteriormente citada, que nos ha parecido apropiado para denominar la postura que afirma que es posible, tanto a nivel psicológico como lógico, decidir creer. Según Pojman, frente a esta postura se encuentran las no volicionistas, que mantienen que creer es el simple resultado de un proceso estrictamente objetivo y racional, donde la libertad de decidir y la subjetividad no tienen ningún papel.

Como antecedentes encontramos a San Agustín (Obras completas: VI. Sobre la predestinación de los santos, cap. 2; XI. Carta 147; IV. De la fe en lo que no se ve. BAC. Madrid. 431. 1971); a Santo Tomás (Suma teológica, I-II, c. 9 art. 1 y 3, c.10 art.1, c. 17 art. 1; Cuestiones disputadas sobre la verdad, c. 14). Posteriormente esta postura será defendida por William James (The Will to Believe and other essays in popular philosophy, New York: Dover Publications, 1956).

4 Esta elección se da en cada salto que da el individuo de un estadio a otro: del estético al moral, y del moral al religioso. 
persona en tanto espíritu, en el que el sentido del creer como fe, sólo puede entenderse desde un nivel existencial que lo diferencia esencialmente del creer meramente epistemológico.

\section{Lo absurdo}

Kierkegaard afirma la posibilidad de aceptar lo imposible o lo absurdo en materia de fe, tomando pie en la famosa máxima de Tertuliano "creo porque es absurdo". Pero cuando nos fijamos en la explicación que da sobre el significado de 'lo absurdo' o 'lo imposible', debemos descartar completamente, como criterio de interpretación de sus textos, todo rechazo al valor de los principios lógicos como tales. No defiende en ningún caso la negación del principio de contradicción. Comentando el absurdo que supondría que el objeto de la fe fuera aquella persona que nos la transmitió y no Dios mismo -el cual nos capacita para entrar en relación con Él-, Kierkegaard alude y utiliza el principio de no contradicción como algo necesario para poder pensar:

Nuestro hipotético supuesto de aquel hecho -recibir la condición de la fe de Dios- y de la relación del individuo con Dios, no contiene contradicción alguna, y el pensamiento puede ocuparse de ello como de la cosa más singular del mundo. Aquella absurda consecuencia [que no podamos recibir la condición de posibilidad de conocer a Dios del mismo Dios] $]^{5}$ encierra en cambio una contradicción, ya que no se contentaron [los que piensan que recibamos tal condición del discípulo que nos da testimonio de la fe] con establecer un absurdo como el de nuestro hipotético supuesto, sino que además, dentro de ese absurdo encierran en cambio una contradicción: que Dios es Dios para el contemporáneo, pero el contemporáneo es de nuevo Dios para un tercero ${ }^{6}$.

Al final de la obra incluso habla directamente de la necesidad del principio de no contradicción:

Aunque fuera mejor dialéctico de lo que soy, tendría un límite; en el fondo es la firmeza en lo absoluto y en las distinciones absolutas lo que convierte a uno en un buen dialéctico; esto es lo que se ha olvidado totalmente en nuestro

5 Lo puesto entre corchetes está añadido por nosotros para explicar la discusión en la que se encuentra la cita.

6 Søren Kierkegaard, Migajas filosóficas o un poco de filosofía, trad. de Rafael Larrañeta. Madrid: Trotta, 2007, p. 105.

Estudios Kierkegaardianos. Revista de filosofía 7 (2021) 
tiempo al suprimir y suprimiendo de hecho el principio de no contradicción, sin percibir lo que ya Aristóteles ponía de relieve: que esta propuesta de suprimir el principio de no contradicción está basada en el principio de no contradicción, porque en caso contrario la propuesta opuesta -que no está suprimido- sería igualmente verdadera (Metafísica, III, IV, 10005b)7 .

Atendiendo a la primera cita que acabamos de señalar, queremos poner de relieve la siguiente afirmación: "no se contentaron con establecer un absurdo como el de nuestro hipotético supuesto, sino que, además, dentro de ese absurdo encierran en cambio una contradicción". Es importante observar una distinción interesante: la que existe entre lo absurdo y lo contradictorio. Si este autor fuera irracionalista y literalmente defendiera la posibilidad de ir contra la razón en su principio más esencial, no haría tal distinción. Y no defendería dicho principio, basándose en Aristóteles, al final de una obra en la cual constantemente propugna la posibilidad de creer lo absurdo de las proposiciones de fe, tal y como hemos mostrado en la segunda cita anteriormente señalada.

Esto nos lleva a entender que el concepto de "lo absurdo" en Kierkegaard no está reñido necesariamente con la posibilidad lógica. Este autor intercambia este término con "lo paradójico", es decir, con aquello que es en apariencia un absurdo lógico, pero no lo es en la realidad. Este fenómeno acontece porque nuestra razón es limitada y no alcanza a descifrar el misterio de lo esencial del cristianismo, que es la unión entre lo eterno y lo histórico en la encarnación de Jesucristo. Lo que se opone al misterio es la especulación, no el pensamiento en general, que sí es capaz de entender lo paradójico como tal: "El cristianismo es lo totalmente opuesto al pensamiento especulativo, porque es lo milagroso, lo absurdo, con la exigencia de que el individuo debe existir en ello y no debe perder el tiempo con indagaciones especulativas" 8 .

En Kierkegaard encontramos dos usos del término 'contradicción'. De forma continua nos dice que existir es vivir en la contradicción' y con ello no se refiere a una contradicción lógica del pensamiento, sino a una cuestión vital del individuo que continuamente debe elegir y tiene posibilidades contrapuestas a cada instante: "Para el pensamiento, la contradicción no se

7 Ibíd., p. 111.

8 Søren Kierkegaard, Postscriptum no científico y definitivo a 'Migajas filosóficas', trad. de Javier Teira y Nekane Legarreta, Salamanca: Sígueme, 2010, p. 371.

9 Ibíd., p. 346. 
sostiene, se resuelve en algo otro y, luego, en una unidad superior. Para la libertad, la contradicción se sostiene, puesto que la excluye" ${ }^{10}$.

El choque con la razón que llamamos paradoja se produce por una cuestión existencial: la pasión infinita que lleva a la razón al choque, puesto que la lleva más allá de sí misma. La pasión que pone en movimiento al pensamiento le lleva a querer, si acepta la posibilidad del escándalo, a descubrir lo que está más allá de sí mismo. Por ello puede incluso perderse en el misterio de la paradoja:

Pero no hace falta pensar mal de la paradoja, porque paradoja es la pasión del pensamiento, y el pensador sin paradoja es como un amante sin pasión: un mediocre modelo. Pero la suprema potencia de la pasión es siempre querer su propia pérdida, la pasión suprema de la razón es desear el choque, aun cuando el choque provoque, en uno u otro modo, su pérdida. Esta suprema pasión del pensamiento consiste en querer descubrir algo que ni siquiera puede pensar. En el fondo esta pasión del pensamiento está presente por doquier en el pensamiento, incluso en el de un individuo concreto, aunque ni siquiera esté pensando y a causa de la costumbre no lo descubra ${ }^{11}$.

Esto se ve con claridad en su obra Ejercitación del cristianismo, que es quizá la obra cumbre de su pensamiento. En ella plantea su postura religiosa. La afirmación de la Encarnación, por ejemplo, núcleo del cristianismo, no es una proposición que podamos obtener por deducción de ninguna otra verdad, ni puede obrarse una síntesis racional entre los términos de la paradoja: 'Dios es eterno' y 'Dios se ha hecho temporal en un individuo particular'. Es lo que denominamos 'misterio' frente a 'problema'. El problema es un conjunto de enunciados que nos dan unos datos, gracias a los cuales podemos encontrar una conclusión lógica. El misterio no es un problema, no es algo que podamos solucionar con nuestra capacidad racional, ya que es una pregunta cuyos datos hemos recibido y por lo tanto no podemos comprender o abarcar cuando se combinan entre sí. Alguien podría objetar cómo es posible que tengamos unos datos que no podemos abarcar, porque entonces no son datos. Lo que recibimos son verdades o enunciados que en sí mismos son comprensibles, pero que combinados con otros parecen irreconciliables. A esto lo denomina Kierkegaard "paradoja”,

10 Søren Kierkegaard, O lo uno o lo otro, trad. de Begonia Saez Tajafuerte y Darío González, Madrid: Trotta, 2007, p.102. Se refiere a que en el ámbito de la libertad se excluye esa unidad superior a la que el intelecto y lo especulativo sí consigue acceder. Kierkegaard realiza la visión hegeliana de la historia en la que no existe libertad, sino que todo transito se realiza por la necesidad lógica de la mediación.

11 Ibíd., p. 51. 
término que define de forma poética como la pasión del pensamiento por perderse, para descubrir lo que está más allá de sí mismo.

Las afirmaciones que forman la paradoja no son producto del razonamiento, sino que son recibidas de forma indirecta a través de la fe o 'condición' de discípulos. Evidentemente, la posibilidad de un DiosHombre, que lo eterno se haya encarnado en un particular, aparece al individuo sin fe como una locura, como algo absurdo. A esta experiencia la denomina 'paradoja absoluta' y ante esta sólo cabe la fe o el rechazo. La primera sólo es posible a su vez gracias a una ayuda de Dios mismo para darnos la condición de la fe y poder entablar relación con É $1^{12}$. Por eso es tan importante para nuestro pensador danés explicar el salto desde la razón meramente especulativa que se ciñe a deducciones lógicas, a un ámbito más allá de sí misma, más allá del ámbito de la lógica. Para la fe religiosa: "es preciso un salto y ruptura racional para poder llegar a la paradoja, a la decisión única de donde emerge la fe" ${ }^{13}$. Esta 'ruptura' racional alude a que la fe no es una cuestión de lógica, ni tampoco es una conclusión a un conjunto de proposiciones más o menos probables -a dicha conclusión la denomina 'opinión'. El ámbito de la fe rompe con la lógica, no porque vaya en contra de ella, sino porque no es un producto de ésta, no se sigue ninguna síntesis que disuelva la paradoja gracias a la lógica. Frente al sistema de Hegel, donde lo religioso queda explicado como evolución del pensamiento, Kierkegaard defiende que la fe no forma ni puede formar parte de un sistema cerrado del pensamiento, porque es una toma de postura libre ante Dios -ser personal-, no la conclusión racional a una evidencia más o menos probable.

Encontramos tres grandes bloques temáticos en la obra de este pensador protestante: los escritos sobre estética, sobre moral y sobre religión. Ampliamente conocidas son las etapas que distingue este autor en relación a la madurez de la persona e incluso del discurso filosófico, que coinciden en estos tres bloques. Pero es fácilmente perceptible que el tema religioso ocupa el lugar primordial para el autor danés, que pretende sin duda "despertar las conciencias dormidas de sus coetáneos"14.

Teniendo en cuenta que Kierkegaard busca pensar y ocuparse de la fe religiosa, se hace necesario para nuestra investigación estudiar de forma más amplia el significado del término creer que abarca tanto el aspecto estético como el religioso, pasando por el moral. Esto se debe a que el término danés Tro que utiliza se puede traducir tanto por $f e$, como por creencia, algo que sin

12 Rafael Larrañeta, 'Razón y Religión en Kierkegaard', notas 73 y 74.

13 Louis P. Pojman, Religious belief and the will, p.153.

14 Ibíd., p. 149. 
duda también ocurre en español donde normalmente son intercambiables. En todo caso, es importante señalar que, para este pensador, padre del existencialismo, los conceptos no están fijados, son entes casi particulares que designan cada uno de ellos aspectos distintos dependiendo de la entidad a la que se refieran y del grado de madurez que tenga la persona que los piensa. Esto último es especialmente relevante con respecto al término fe: el concepto no es independiente de la persona que lo sustenta, porque la verdad está íntimamente ligada a la apropiación de ésta por parte del sujeto. Kierkegaard insiste en que Cristo no proclamó que supiera la verdad, sino que era la verdad:

El ser de la verdad es la duplicación en ti, en mí, en él, de manera que tu vida, la mía y la suya aproximativamente -en conato de ello- exprese la verdad; que tu vida, la mía y la suya de una manera aproximativa sea el ser de la verdad, como la verdad en Cristo: una vida, pues Él era la verdad.

Y por eso la verdad, entendida cristianamente, no es naturalmente lo mismo que saber la verdad, sino ser la verdad. Porque a despecho de toda la filosofía moderna hay que afirmar una diferencia infinita entre esos dos modos, la cual se ve admirablemente como nunca en la relación de Cristo a Pilatos; pues Cristo no podía, o lo podía sólo falsamente, responder a la pregunta: ¿qué es la verdad? Precisamente porque en su caso no se trataba de alguien que supiera la verdad, sino que era la verdad. Y no porque no supiera lo que era, sino que cuando se es la verdad y la exigencia consiste en ser la verdad, es una falsedad saber la verdad ${ }^{15}$.

Hay un concepto de verdad en sentido objetivo y un sentido de verdad en sentido subjetivo, nos dice Kierkegaard. En el primero, el sujeto se pierde a sí mismo contemplando el objeto, como por ejemplo en la ciencia. En el segundo el sujeto es imprescindible, por ejemplo, en la filosofía o en fe, puesto que lo real se descubre en él en tanto se apropia de la verdad descubierta. En todo caso, nunca la verdad se identificará con la subjetividad, tal y como sucede con el idealismo que tanto criticará Kierkegaard de Hegel. El análisis de los diversos modos de creer a los que se refiere en su obra, nos ayudará a entender mejor la implicación de lo subjetivo en su pensamiento.

15 Søren Kierkegaard, Ejercitación del cristianismo, trad. de Demetrio G. Rivero, Madrid: Guadarrama, 1961, p. 279-80. 


\section{Tipos de actos de creer $^{16}$}

A) En primer lugar encontramos un tipo de creer que se sitúa en el nivel estético. Es un modo de percibir la realidad que se centra en la situación de la persona y sus sentimientos, partiendo de un egoísmo ingenuo. No es opuesto a lo racional, pero se basa en la percepción inmediata (sin mediación racional) de la realidad mediante los sentimientos. A través de ese modo de percibir la realidad, la persona puede engañarse pensando que toma decisiones personales, pero no es así. Sólo se deja llevar por sus preferencias afectivas. La persona en ese caso no quiere decidir conscientemente dar el salto a lo moral, aunque de forma inevitable termina eligiendo, incluso sin ser consciente de ello, puesto que en la vida elegimos continuamente:

El instante de la elección es para mí de la mayor seriedad, no tanto en razón del escudriñamiento de aquello que en la elección se presenta separado, no en razón de la variedad de pensamientos enlazados a cada término, sino porque se corre el riesgo de que, en el instante siguiente, ya no esté a mi alcance poder elegir, que algo que ya ha sido vivido deja de volver a ser vivido; uno se equivoca, en efecto, si cree que alguien puede mantener por un instante su personalidad en blanco, o, en un sentido aún más estricto, detener su vida personal. Antes de que uno elija, la personalidad está ya interesada en la elección: la personalidad, o los poderes ocultos en ella, elige de manera inconsciente ${ }^{17}$.

B) El segundo modo de creer acontece en la etapa moral. Este afirma lo racional en el orden moral. Al igual que en el nivel estético, también acontece de forma instintiva e inmediata, pero, puesto que se da tras la reflexión, se caracteriza como una 'segunda inmediatez'. Pero el individuo todavía no ha llegado a la total autonomía y seguridad, propia del acto de fe religioso. Cree hasta donde la reflexión racional puede llevarle, pero no ha chocado en ningún sentido con contradicciones.

Esta etapa es muy importante, puesto que las elecciones son fundamentales para la configuración de la personalidad ${ }^{18}$. Se puede auténticamente elegir desde el punto de vista ético, pero sin perder el pathos, la energía del corazón. La etapa moral no debe suprimir la estética, sino otorgarle la dimensión ética a través de la decisión reflexiva. Pero no podemos dar este salto sin abrirnos a la posibilidad del bien y del mal. El

16 Rafael Larrañeta, 'Razón y Religión en Kierkegaard', p. 71-73.

17 Søren Kierkegaard, O lo uno o lo otro, p.156.

18 Ibíd. 
que permanece en la etapa estética, elige la indiferencia; el que salta a la visión moral del mundo, opta por la existencia del bien y del mal, entre los cuales posteriormente deberá elegir.

A su vez, el que posterga la elección, se aleja cada vez más de Dios y de la etapa religiosa ${ }^{19}$. Es en el actuar donde se produce la verdad en sentido subjetivo ${ }^{20}$. Y la elección es imprescindible, puesto que quizá en el momento siguiente ya no pueda hacerlo. Este es uno de los inconvenientes de haber convertido el problema de Dios en un problema especulativo y no vital -pasional y moral-. La especulación no hace sino retrasar la decisión y con nuestra vida y comportamiento nos podemos ir alejando cada vez más de Dios.

Ya ves, tú mismo admites no haber elegido precisamente la mejor parte; pero lo cierto es que no has elegido, y punto, o que has elegido en un sentido impropio. Tu elección es una elección estética, una elección estética no es una elección. En definitiva, el elegir es expresión propia y rigurosa de lo ético... Siempre que se trata de una alternativa en sentido escrito, uno puede estar seguro de que lo ético está en juego. La única alternativa absoluta es la elección entre el bien y el mal, y ésta es absolutamente ética. En cuanto a la elección estética, o bien es algo totalmente inmediato y, por consiguiente, no es ninguna elección, o bien se pierde en lo múltiple. (...) Cuando un hombre sopesa de manera estética una multitud de problemas vitales, como tú mismo en lo precedente, no obtiene sencillamente una alternativa, sino una multitud de ellas, (...) cuando no se elige de manera absoluta se elige sólo para el momento, y, por ende, se puede elegir otra cosa en el instante siguiente ${ }^{21}$.

Pero una vez que el ser humano se encuentra en la etapa moral, el paso a lo infinito sólo será posible desde la decisión de la apertura a este. Debemos elegir de nuevo y siempre entre dos poderes: Dios o el mundo ${ }^{22}$. Podemos incluso elegir en un primer momento ambos y caer en un panteísmo u optar por la elección absoluta. La última nos lleva a la paradoja entre lo que el mundo nos propone como racional y lo que va en contra de todos nuestros esquemas racionales llevándonos a renunciar a su explicación. Lo sepamos o no, vivimos en la contradicción: el sufrimiento la saca a relucir porque

19 Søren Kierkegaard, Los lirios del campo y las aves del cielo, trad. de Demetrio G. Rivero. Madrid: Guadarrama, 1963, p. 215.

20 Søren Kierkegaard, El concepto de la angustia, trad. de Darío González y Oscar Parcero. Madrid: Trotta, 2016, p. 245.

21 Søren Kierkegaard, O lo uno o lo otro, p.157.

22 Søren Kierkegaard, Los lirios del campo y las aves del cielo, p. 97. 
en él experimentamos el choque entre el mundo, que busca el placer y la felicidad inmanente, y la fe en Dios que es trascendente a aquel.

C) El tercer y cuarto tipos de creer se refieren al ámbito religioso en sentido amplio ${ }^{23}$, que divide en 'religiosidad A' y 'religiosidad B'. En el primero aparece la paradoja en su primer destello, pero permanece todavía dentro de la inmanencia. A esta religiosidad pertenece el paganismo culto de Sócrates, al que tanto admira Kierkegaard. Sabemos se encuentra en el ámbito religioso porque hay una implicación entre lo eterno y lo temporal, pero sin romper con los esquemas racionales de la inmanencia. En la 'religiosidad B' ya se cree en la paradoja de la encarnación. Ésta asume la existencia del absurdo y es consciente, en palabras de Hume ${ }^{24}$, 'del continuo milagro que es su propia persona, los principios de su entendimiento, y toma la determinación de creer lo que es más contrario a la costumbre y a la experiencia'; este acto libre de adhesión a la paradoja es propiamente la fe religiosa: "la fe es la objetiva incertidumbre debida a la contrariedad del absurdo sostenida por la pasión más intensa de la interioridad ${ }^{25}$.

En esa opción la razón postulada por el racionalismo encuentra algo que choca con ella, que le lleva la contraria, puesto que la sorprende con verdades que ella no ha podido llegar ni a imaginar. Por ello "en lo absoluto encalla la razón"26: "El Dios-hombre es la paradoja, absolutamente la paradoja; por lo cual es completamente seguro que la razón tiene que paralizarse en su cercanía"27.

D) La quinta acepción del término creer se refiere a la opinión, a la que no dedica apenas esfuerzo porque "no es importante para sus propósitos. Dicha opinión se basa en lo probable y es un estado psicológico que es simplemente necesario para saber si debo o no coger el paraguas, o tomar

23 Es importante distinguir la creencia como contenido de la fe -en este caso, la existencia de Dios, que daría lugar a 'creer que Dios existe'-, de la fe en Dios, que es el acto a través del cual accedo a él de existente a existente.

24 "So that, upon the whole, we may conclude, that the Christian Religion not only was at first attended with miracles, but even at this day cannot be believed by any reasonable person without one. Mere reason is insufficient to convince us of its veracity: and whoever is moved by Faith to assent to it, is conscious of a continued miracle in his own person, which subverts all the principles of his understanding, and gives him a determination to believe what is most contrary to custom and experience." David Hume, X. Of Miracles. An enquiry concerning buman understanding. Cfr. Louis P. Pojman, Religious belief and the will, p. 64.

25 Søren Kierkegaard, Concluding Unscientific Postscript, p. 540.

26 Søren Kierkegaard, Ejercitación del cristianismo, p. 176.

27 Ibíd., p. 129. 
más o menos calorías en mi dieta" ${ }^{28}$. Es decir, es la opinión de la que tanto hablan autores como Locke, Hume... la cual se basa en la mera probabilidad.

E) El sexto significado de creer, es 'el órgano para aprehender la historia', que hace presente a la conciencia el pasado, lo cual ya incluye la imaginación y la voluntad como capacidades para recrear el pasado. "La creencia no es una conclusión sino una resolución: no es tanto una forma de conocimiento sino un acto libre, una expresión de la voluntad" 29.

F) Finalmente, el séptimo significado de creer aparece en los últimos escritos del pensador danés y se refiere al aspecto del creer como esperar, el cual no existe sin riesgo. Subraya el aspecto de posibilidad frente al de probabilidad de la opinión/creencia. Este aspecto subjetivo de esperanza se halla también en el acto de fe religioso: "la fe es esencialmente aferrarse a la posibilidad'30.

En Migajas filosóficas o un poco de filosofía el pensador danés establece ciertos grados en la fase final del movimiento racional que dará paso al acto o salto de la fe, el cual sólo puede acontecer desde el impulso de la subjetividad de una persona libre. Tal y como nos los describe Larrañeta, nos encontramos con tres etapas:

1. La razón "objetiva" ha cumplido su trayectoria, lo que significa que no hemos negado su curso, sino que hemos seguido su "dis-curso", su proceder y que hemos alcanzado el límite.

2. La razón percibe que no puede ir más allá, que choca con algo que por sí misma no puede superar. En este momento se detiene, como le pasó a Sócrates en un instante de su vida.

3. ¿Qué es eso con lo que topa la razón? La respuesta es dubitativa. Kierkegaard lo designa de dos maneras: Es lo desconocido, algo que la razón no logra reconocer. Pero también -dice- es algo situado "fuera", algo que se sitúa en la diáspora y que por ende se hace inaccesible al pensar. ¿Qué acontece entonces? Varias cosas que adquieren sentido propio. En primer lugar, la razón no puede pensar eso que está ahí fuera, y no puede pensarlo porque es absolutamente diferente, y lo absolutamente diferente es impensable

28 Ibíd.

29 Søren Kierkegaard, Fragments. 'Interlude', p.102f. En esta obra rechaza la necesidad hegeliana de la historia y la afronta desde el concepto de libertad. Cfr. Louis P. Pojman, Religious belief and the will, p.73.

30 Søren Kierkegaard, Papers IX A 311. Cfr. Louis P. Pojman, Religious belief and the will, p.74. 
por ella y para ella. Pero la razón se atreve a llamar, a nombrar eso que aparece ante ella en la "diáspora" y el nombre elegido es "el Dios". Esa aparición de "el Dios" en los lindes de la razón produce un efecto singular: el sujeto penosamente cambia, se transforma, se muda. Es algo similar a lo que sucede al enamorado, por muy razonador o pensador abstracto que sea. Su vida se ve totalmente cambiada, aunque racionalmente no pueda explicarlo ${ }^{31}$.

Kierkegaard nos plantea el recorrido del proceso racional hasta llegar a sus propios límites y va describiendo cómo es vista la fe desde su pura inmanencia. Y una vez llegado al límite con lo desconocido, tiene dos opciones: empecinarse en entenderla y no querer dar el paso hacia ella sin su comprensión, o dar el salto hacia lo no comprendido o desconocido, es decir, sostener la paradoja desde la fuerza de la interioridad apasionada. Para ello la subjetividad es imprescindible, ya que es un salto que sólo puede dar la persona. Y es un salto porque no hay continuidad racional, no es una conclusión a un discurso filosófico, sino que es una verdad más allá de los límites de lo que el mundo considera razonable. No afirma que sea irracional, sino que esas proposiciones de la fe que implican un misterio o paradoja, cuando se combinan y se muestran ante el proceso racional (Jesús es verdadero Dios y verdadero hombre, por ejemplo) sólo pueden ser afirmadas arriesgándose a saltar libremente hacia la fe. Kierkegaard no niega que haya ciertas evidencias racionales a favor de la fe, que la hacen posible e incluso probable, pero no nos llevan al objeto de la fe, que no es una relación intelectual con una doctrina, sino la misma persona de Jesucristo.

En el salto por gracia ${ }^{32}$ el existente queda transformado por el encuentro. Y lo que era paradoja y escándalo se convierte en la fuerza de la pasión. Como ejemplo encontramos Temor y temblor, donde quedaría descrito el impacto que recibe la sensibilidad de Johannes el silentio ${ }^{33}$ a partir de la

31 Rafael Larrañeta, 'Razón y Religión en Søren Kierkegaard', p.162.

32 Es fundamental entender que dicho salto no es obra sólo de la voluntad, sino que es motivado y afianzado por la ayuda y la misma presencia de Dios. La fe provoca el encuentro entre dos existentes y transforma a la persona: es un milagro no explicable por los datos asequibles a la razón.

33 Los seudónimos que presenta Kierkegaard en su obra tendrían por objeto identificar posturas posibles, pero que no se identifican con él, tal y como él mismo nos advierte: "Así, en los libros seudónimos, no hay ni una sola palabra mía. No tengo opinión de ellos excepto como tercero, ningún conocimiento de su significado, excepto como lector, ni la más remota relación personal con ellos. (...) Por tanto, si a alguien se le ocurre querer citar un pasaje particular de los libros, es mi deseo, mi ruego, que sea tan amable de citar los respectivos nombres de los autores seudónimos, no el mío”. Postscriptum. Apéndice. p. 604-605. 
fe de Abraham. Su acción intentando sacrificar a Isaac, se presenta como contraria a la ética universal kantiana, a los ojos de alguien que todavía no conoce existencialmente a Dios. El proceso de lo racional en su estadio estético delante de una acción que va más allá de la ética aparece como un escándalo, una inmoralidad. Porque lo que pretende Kierkegaard es llevar a la subjetividad, al individuo como tal -con sus sentimientos y con toda su vida-, más allá de la inmanencia, a mirar de frente a Dios.

Hasta aquí hemos descrito las distintas acepciones del término creer para Kierkegaard, así como su diferencia y relación con el salto de la fe. Además, hemos pretendido responder al supuesto carácter irracionalista de este pensador danés. A continuación, intentaremos describir el papel del dinamismo del querer que acontece en la subjetividad y que posibilita el salto a la fe, sin negar el valor que tiene la verdad para nuestro autor en dicho acto.

\section{La verdad subjetiva}

Para Kierkegaard sólo desde la subjetividad es posible encontrar la verdad, y muy especialmente en el caso de la verdad suprema. Esta afirmación suya no supone en ningún caso que sea la propia de un relativista, sino que sólo desde la conciencia y la interioridad más profunda del ser humano, donde se encuentra lo más profundo de nuestra existencia, puede darse el encuentro con la verdad auténtica, que reside únicamente en la relación con Dios. El objeto de la fe no es conjunto de verdades, un mensaje, sino que Kierkegaard considera que es el encuentro y la relación con el mensajero: Jesús. Sólo en el encuentro de existente con existente se puede conocer a Dios y dejarse transformar por Él. A esta posibilidad que otorga como

Esta postura sobre los pseudónimos es sostenida, tanto por Asunción Herrera Guevara, en 'Teorema', vol. XXII/3, 2003, p.101-114; como por Catalina Elena Dobre, la cual nos explica que "Kierkegaard no quiere hablar e imponer su verdad al lector; al contrario, quiere ocultarse tras una máscara, tras un seudónimo y para él es de vital importancia que el lector entre en relación con el seudónimo y lo conozca, conociendo así la forma de pensar de uno u otro seudónimo. (...) Cada uno tiene una manera peculiar de entender la existencia. Con estas creaciones, con estos autores, Kierkegaard rompe con la autoridad del saber dejando espacio para el descubrimiento de la existencia que el lector hará por sí mismo; en otras palabras, el lector está invitado a juzgar por sí mismo”. Pascal, Kierkegaard, Buber. Un nuevo modo de filosofar: la relación como fundamento de la existencia. Colección Persona, Madrid: Fundación Enmanuel Mounier, 2013, p. 61. Véase también en este sentido: M. Taylor, Kierkegaard's Pseudonymous Authorship, Princeton University Press: Princeton, 1973, y C. S. Evans, Kierkegaard's 'Fragments' and Postscript', Humanities Press: Nueva York, 1983. 
regalo la fe la denomina nuestro autor 'la condición' de discípulo ${ }^{34}$. Tener fe no es afirmar un conjunto de verdades sino haberse encontrado con el Señor y seguirle como discípulo:

Si conozco la doctrina de Spinoza, en el instante de conocerla no me ocupo de Spinoza sino de su doctrina, mientras que en otro momento estoy ocupado históricamente con él. El discípulo en cambio se relaciona con aquel maestro creyendo que éste se ha ocupado eternamente de su existencia histórica.

Supongamos ahora que acontece como lo habíamos planteado: que aquel maestro concede al discípulo 'la condición', con lo cual el objeto de la fe no es la doctrina, sino el maestro ${ }^{35}$. Ser cristianos, nos dice, se define subjetivamente de este modo:

La decisión depende del sujeto: la apropiación es la paradójica interioridad que es específicamente diferente de toda otra interioridad. Ser cristiano se define no por el "qué" del cristianismo, sino por el "cómo" del cristiano. Este "cómo" sólo puede admitir una cosa, la paradoja absoluta. (...) Tener fe queda específicamente determinado de manera diferente de cualquier otra apropiación e interioridad. La fe es la incertidumbre objetiva en el escándalo de lo absurdo, firmemente mantenida en la pasión de la interioridad, pasión que es la relación de la interioridad intensificada al máximo. Esta fórmula sólo encaja en aquel que tiene fe, en nadie más ${ }^{36}$.

\section{Lafe}

La persona a través de su conciencia encuentra la verdad en la incertidumbre objetiva, puesto que no se nos da Dios plenamente, de forma directa, a la razón. No podemos abarcar a Dios. Y ¿qué es la fe?: "mantener

${ }^{34}$ A este tema dedica el capítulo IV de Migajas, p. 67-79. Kierkegaard se plantea la cuestión de la unión de lo temporal y lo eterno en el cristiano. Si a través de cualquier momento de la historia no se pudiera acceder a lo eterno -que se ha manifestado plenamente en Jesús- sino que hubiera que pertenecer a su tiempo histórico, entonces el resto de generaciones no tendríamos la posibilidad de conocerlo y entablar relación con lo eterno a través de lo temporal. Para Kierkegaard tener la posibilidad de ese encuentro entre existente y existente es denominado 'la condición'. Es decir, 'la condición' es hacerse contemporáneo de Cristo, es afirmar la posibilidad en el momento histórico al que pertenecemos de acceder al encuentro con Jesús a través de la fe. Esta condición por supuesto es un misterio y es denominada por Kierkegaard como 'la gran paradoja'.

35 Søren Kierkegaard, Migajas, p.73.

36 Søren Kierkegaard, Postscriptum no científico y definitivo a 'Migajas filosóficas', p. 591.

Estudios Kierkegaardianos. Revista de filosofía 7 (2021) 
firme la posibilidad", creer en la posibilidad de abolir el pecado, la muerte y el sufrimiento. Creo precisamente, porque no puedo abarcar objetivamente a Dios, puesto que no es un objeto más. La preposición $e n^{37}$ que antecede a Dios no es aleatoria. Quizá es la preposición que mejor caracteriza la relación entre Dios y el creyente. Porque la fe es la respuesta del sujeto en la presencia ya dada por Dios. Y esto acontece no por un proceso racional, ni por simple mérito de una elección libre, sino como gracia.

Pero una vez que Dios se presenta y tomamos conciencia de su presencia, la respuesta por parte del ser humano se da como salto, como riesgo, desde la confianza. Es decir, la aceptación no se da por razones intelectuales o evidencias de este tipo. Puesto que la religión cristiana afirma que Dios es un ser concreto y personal, pongamos el ejemplo por analogía del encuentro entre dos personas: en ese encuentro yo no tengo evidencia intelectual sobre

37 Las proposiciones que anteceden a la fe religiosa conllevan connotaciones muy importantes respecto a ésta. El concepto de fe religiosa surge en el ámbito judío. El término que utiliza el hebreo y la tradición rabínica es 'emuna' tal y como nos pone de relieve en su interesante obra 'dos modos de fe' Martin Buber. Emuna hace referencia, según este pensador judío, a un estado de confianza dada en la permanencia de la relación del pueblo con Dios. La confianza se da en la presencia; en este sentido habría que utilizar también la expresión 'creer en Dios' con el sentido de confiar en él. Es conocida también la crítica que realiza Buber a la concepción de la fe cristiana, que, según él, fue elaborada por Pablo por influencia del helenismo. Para Buber, la concepción griega es intelectualista y proposicional. De tal manera que se expresa en un 'creer- que-tal cosa- es de un modo'. Santo Tomás de Aquino, expone en la Suma Teológica que hay tres aspectos en el acto de fe. Estos aspectos se pueden expresar adecuadamente según los términos "credere Deo", "credere Deum" y "credere in Deum". El primero, en cuanto es el objeto material de la fe, y esto se expresa con la fórmula "creer sobre Dios" ("credere Deum"); porque nada se nos propone para creer, a no ser en cuanto dice relación a Dios. El segundo aspecto es, no el objeto material, sino la razón formal de ese objeto, o el llamado objeto formal, que es el medio o la luz por la que el entendimiento asiente a dicho objeto material; esto se expresa con la fórmula "creer a Dios" ("credere Deo"). En efecto, el objeto formal de la fe es la verdad primera, Dios mismo, al cual se adhiere el hombre, para asentir a las cosas que son objeto de fe. El tercer aspecto aparece cuando se pone el objeto de fe en relación con la voluntad que mueve al entendimiento al acto de fe; este tercer aspecto se expresa con las palabras "creer en Dios [con amor]" ("credere in Deum"). De esta forma, podemos decir que la expresión de confianza generada por la presencia de Dios y que se expresa como ‘creer en’ Dios no es ajena a la concepción cristiana, puesto que se entiende también como permanencia en Dios una vez que se presenta como gracia. Pero indudablemente este 'creer en' que genera el acto de aceptación, implica también cierto conocimiento de Dios mismo. Pero este conocimiento es un reconocimiento, no es anterior al salto de la fe misma ni al estado de confianza de Buber. En conclusión, el significado más pleno de fe se encuentra en la expresión que utiliza Kierkegaard de 'creer en' puesto que engloba la relación existencial personal, la confianza generada por dicho encuentro, el salto de aceptación libre, la posibilidad de reflexión intelectual de ésta. Es decir, contiene la respuesta de la persona humana integral. 
quién es esa persona, sino que es en la misma relación donde la descubro. Pero este descubrimiento no se da en la distancia que propicia una relación intelectual; se da en tanto los dos somos personas, por lo que sólo a través de la propia relación, hablando y estando en compañía de esa persona, puedo llegar a conocerla.

Para Kierkegaard, en la verdad, que es la realidad en tanto dada en la conciencia, siempre hay incertidumbre ${ }^{38}$. Y mucho más en el caso de la fe, en tanto Dios, como realidad dada en la conciencia, no se deja aprehender como mero objeto cognoscitivo. Frente a esta incertidumbre objetiva, este pensador nos propone arriesgar. Creer es arriesgar por la verdad para encontrarla en $-\mathrm{y}$ no, tras- el salto de la fe.

\section{El acto libre de la fe}

Puesto que este salto implica a toda la persona en sus dimensiones fundamentales: reflexión racional -por supuesto para Kierkegaard hay unos contenidos proposicionales que se entienden separadamente, pero cuya unión resulta paradójica ${ }^{39}$ : por ejemplo, que Dios se haya hecho individuo particular-; corazón- dice que la verdad está sostenida por la pasión y somos atraídos por ella-; y compromiso o decisión, el cual propiamente es el salto

38 Aclaremos que aquí no habla de la mera certeza de que Dios existe, sino de conocerle a través de una relación personal, que es el modo de conocimiento que se da en la fe cristiana: relacionarse con el misterio escondido de Dios. De esta forma, al entrar en la intimidad de esa relación, siempre hay incertidumbre porque el ser humano no puede llegar a conocerlo plenamente.

39 Es importante que se presenten como tales para atraer la atención y tener que tomar partido. Desde nuestro punto de vista, podríamos hablar de la necesidad que hay para este autor de que la fe produzca un choque psicológico en un mundo donde se da por sentada la religiosidad o se da por supuesto que se sabe lo que es. Pero no es una doctrina meramente, y, por ello, es importante que nos lleve a tomar una decisión: la posibilidad del escándalo es la posibilidad psicológica de la fe: "la posibilidad del escándalo es la defensa y el escudo de la fe, es de tal manera ambivalente que toda humana razón tiene de una manera u otra que llegar a la perplejidad, debe chocar contra ella, o para escandalizarse o para creer". Søren Kierkegaard, Ejercitación del cristianismo, p. 157. En este sentido también interpreta la expresión de Jesús de que él es "signo de contradicción". Los milagros atraen la atención hacia su persona. Ésta se presenta como siendo otra cosa, la cual está en contradicción con lo que se ve de forma inmediata. Jesús verdaderamente es también Dios y esto choca con lo que se ve de forma inmediata (sólo un hombre). El signo, puesto que debe ser interpretado, hará "patente los pensamientos de los corazones". Ejercitación, p. 182. "La comunicación indirecta te enfrenta a una elección: querer creer o no”. Ibíd., p. 195. 
de la fe. La persona debe poner enteramente en juego su vida, apropiándose de la verdad mediante sus decisiones y acciones:

Ningún hombre sabe más de la verdad que lo que él sea de la verdad. Ya que saber la verdad es propiamente imposible, pues si se sabe la verdad ha de saberse que la verdad es serlo. (...). El saber se relaciona con la verdad, cuando yo estoy falsamente fuera de mí; pues en mí, es decir, cuando yo soy verdaderamente en mí (no falsamente fuera de mí) la verdad consiste en un ser, en una vida. (...) Lo que significa que sólo conozco de verdad la verdad si ella se hace una vida en $\mathrm{mí}^{40}$.

La fe no puede resultar directamente o de una consideración científica directa; al contrario, en esa objetividad se pierde el interés infinito, personal y apasionado que es la condición de la fe $\mathrm{e}^{41}$.

Kierkegaard hace mucho hincapié en que la fe es patética y dialéctica. Es decir, que no debemos perder el interés o pasión por lo infinito. Esta pasión nos llevará más allá de nosotros, hacia lo religioso o paradójico mediante la reflexión, y culminará en la transformación de la persona. Y puesto que sabemos que la verdad se encuentra en esa transformación, debemos dejar a un lado las especulaciones que nos alejen o dilaten en el tiempo la decisión o el salto a lo religioso-infinito.

En la relación con otra persona, lo especulativo está de más y la única evidencia que puedes encontrar se encuentra en la propia relación: "La relación con Dios tiene una sola evidencia: la propia relación con Dios; todo lo demás es equívoco" ${ }^{42}$. De esta manera, no es que niegue la participación de la reflexión y la inteligencia, sino que traslada la cuestión al terreno de lo vital, de lo humano en sentido integral, al terreno de las relaciones personales cuyo núcleo es el corazón. Lo intelectual es secundario y no dirime la cuestión. Las evidencias se encuentran en el terreno del corazón cuando se abre libremente a la realidad de Dios. Y es así como encuentra la evidencia. Kierkegaard invierte el orden establecido por el intelectualismo: razón- feamor. Sólo desde el corazón apasionado encontraremos a Dios y eso nos basta. No es necesario comprender más que la evidencia de esa relación, porque entonces los más inteligentes tendrían ventaja para llegar a Dios y eso es gnosticismo ${ }^{43}$. Debemos dejar a un lado ese intelectualismo, porque sólo encontramos cosas inmanentes y nosotros buscamos lo trascendente:

40 Søren Kierkegaard, Ejercitación del cristianismo, p. 280.

41 Søren Kierkegaard, Postscriptum, p. 41.

42 Ibíd., nota a pie p. 435.

43 "Otorgarle supremacía al pensamiento sobre todo lo demás es gnosticismo", Postscriptum, p. 337. 
El malentendido continuamente consiste en el espejismo de que el carácter incomprensible de la paradoja se supone que está conectado con la diferencia entre una mayor o menor comprensión, con la comparación entre mentes buenas o malas. La paradoja está conectada esencialmente con ser persona, y cualitativamente con cada persona en particular, tanto si ésta entiende mucho o poco ${ }^{44}$.

Recordemos que la lucha más importante a lo largo de toda su obra se realiza contra el intelectualismo religioso de Hegel, de tal manera que llega a afirmar que 'la especulación es lo más opuesto al cristianismo' ${ }^{45}$. Entiende por especulación la reflexión que aleja al sujeto del conocimiento para buscar la objetividad. Esto es legítimo en la ciencia, pero en los saberes donde la subjetividad es necesaria para encontrar la verdad, como es el caso de la ética, la filosofía o la religión, hay que reconquistar lo subjetivo para encontrar la verdad: "la subjetividad es la verdad" ${ }^{46}$, repite incesantemente. Y una vez recuperado este aspecto, es necesario que se dé un movimiento dialéctico hacia la síntesis obrada por el individuo a través de la decisión. La decisión es una ruptura racional que nos lleva de la posibilidad a la realidad que buscamos. No hay movimiento sin acción y decisión, y éstas no se dan en el pensamiento como tal:

La intelectualidad se muestra muy rigurosa al transformar el pensamiento en acción, pero este rigor es una falsa alarma, puesto que permitir que la intelectualidad cancele la acción es un relajamiento. (...) Haber pensado algo bueno, ¿significa haberlo realizado? En absoluto, pero tampoco es lo externo lo que determina el resultado porque aquel que no posee un centavo puede ser tan compasivo como una persona que entregue su reino. (...) Tener fe en Dios, ¿significa pensar en lo glorioso que es tener fe, pensar en la paz y la seguridad que Dios confiere? En absoluto. Incluso desear, para lo cual el interés del sujeto es harto más evidente, no significa tener fe, no llega a ser un $\operatorname{acto}^{47}$.

En la obra de Hegel es el absoluto el que de forma necesaria realiza la ‘mediación' o ‘síntesis' entre los opuestos. En Kierkegaard es el sujeto y de forma libre el único que puede realizarla. El ser humano se encuentra disperso entre los opuestos porque por la libertad se abre a una posibilidad infinita. Esto le genera angustia, que no es más que el vértigo ante esa nada

$\begin{array}{ll}{ }_{44} & \text { Ibíd., p. } 548 . \\ 45 & \text { Ibíd., p. } 359 . \\ { }_{46} & \text { Ibíd., p. } 191 . \\ 47 & \text { Ibíd., p. } 335 .\end{array}$

Estudios Kierkegaardianos. Revista de filosofía 7 (2021) 
que supone la posibilidad. Pero esa angustia no es negativa, sino que es ineludible en la experiencia humana y nos orienta hacia lo eterno. Es un momento de la dialéctica que nos puede llevar a la salvación si el espíritu opta por la fe y llega a la unidad como individuo superando las oposiciones:

La meditación sobre la angustia, la libertad y el pecado es ocasión para suscitar un movimiento interior orientado al cambio, que implica salir del ámbito de lo demoníaco al cual ingresa el ser humano al cometer el pecado y empezar a sufrir la angustia por el bien. El hombre angustiado anhela recuperar su libertad y su relación con Dios, que es fundamental en él y que pierde al entrar al ámbito lo demoníaco ${ }^{48}$.

Kierkegaard distingue entre el especulativo y el sabio sencillo. El primero quiere basar su decisión en una mera conclusión lógica y nunca alcanza su objetivo, puesto que la evidencia religiosa no es algo directo, sino que acontece cuando el sujeto ha obrado la síntesis y ha dado el salto. El sabio sencillo es el que es consciente de la paradoja, de la oposición de los contrarios y de que debe elegir. No se pierde en elucubraciones, porque es consciente de la inutilidad de ellas si no participa como sujeto de la verdad en cuestión. El sabio sencillo se sumergirá en la tarea de entender la paradoja en cuanto paradoja, y no se lanzará a explicarla mediante la comprensión de que ésta no existe:

Yo he tenido la posibilidad de poder dedicar mucho tiempo a la investigación y a la reflexión y, no obstante, la summa summarum de todo esto es, en el mejor de los casos, que no puede ser de otro modo, que tiene que ser incomprensible. Pero mira, esta diferencia no puede entristecerte (...) Mi ventaja, si se la considera como fruto del estudio, es como para reír y llorar a la vez por ella. Sin embargo, tú no debes desdeñar nunca dicho estudio, como yo tampoco arrepentirme del mismo, ya que, al contrario, lo que más me complace es sonreír y, entonces justamente, entregarme de nuevo entusiasmado al esfuerzo del pensamiento ${ }^{49}$.

Cuando nuestro autor habla de dejar a un lado la razón, es porque piensa, frente a Kant, que ésta no es autónoma, y que debe ser humilde frente a su Creador. Dicho salto, que es una decisión ética racional-dejar a un lado la especulación para resolver la paradoja- se muestra de nuevo insuficiente, puesto que necesita de 'la condición'. La paradoja de la fe no puede

48 José Rey de Castro, Synesis, v. 10, n. 1, p. 147-165, Universidad Católica de Petrópolis, Petrópolis, 2018.

49 Ibíd., p. 228. 
resolverse en una síntesis con las solas fuerzas del individuo, sino que es necesaria la fe como don de Dios. El ser humano llega de lo múltiple finito a la unidad y lo infinito, sólo con la ayuda de su Creador: éste es el don de la fe que Kierkegaard denomina 'la condición'.

Por lo tanto, entendemos que no es un irracionalismo lo que plantea Kierkegaard, puesto que plantea la necesidad de pensar en la dialéctica, en la paradoja, para poder apreciar el 'escándalo de la cruz'. Es cierto que plantea la no necesidad de buscar la evidencia para dicho salto, pero porque sabe que ésta se encuentra en el salto mismo, en la relación misma con Dios. No defiende la irracionalidad de este acto, puesto que tiene claro que la fe cuenta con muchas probabilidades, aunque nunca con un pretendido conocimiento objetivo de Dios, puesto que dejaría de ser fe:

Supongamos ahora que hay un hombre que dice que tiene fe, pero que quiere hacer que su fe sea evidente, que quiere comprenderse a sí mismo en su fe. Comienza de nuevo la comedia. El objeto de la fe llega a ser casi probable, luego poco menos que probable y finalmente llega a ser probable: suma y extremadamente probable. Se encuentra preparado y se atreve a decir de sí mismo que su fe no es la de los zapateros, sastres y demás gente sencilla, sino que él, además, se ha comprendido a sí mismo en su fe. Extraña comprensión ésta. En cambio, aparte de que creía, ha conseguido saber otra cosa sobre la $\mathrm{fe}$, ha conseguido saber que ya no cree, pues él casi sabe, poco menos que sabe, que casi sabe en grado extremo y sumo ${ }^{50}$.

Pero nunca dicha probabilidad nos lleva por sí misma a la fe-puesto que ya no sería tal, sino tan solo un producto humano-. Encontrar la verdad sobre la fe es una cuestión del sujeto porque el cristianismo no es como tal una doctrina, sino el encuentro del existente individuo con el existente Dios, el cual se presenta como personal.

En las cuestiones de índole personal -por ejemplo, una amistad- la evidencia a favor de una persona, no se encuentra hasta que salimos a su encuentro, hasta que nos decidimos a acercarnos a ella. Todos los datos y evidencias especulativas que puedan ofrecernos para que entremos en contacto con ella son inútiles mientras no lleguemos a conocerla. En efecto, es necesaria una ruptura racional, la de la propia inmanencia del sistema hegeliano que no conduce más que a un panteísmo. El salto de la decisión rompe con nuestros esquemas, planteamientos y elucubraciones porque son sólo inmanentes y nosotros buscamos el encuentro con lo trascendente.

$50 \quad$ Ibíd., p. 212.

Estudios Kierkegaardianos. Revista de filosofía 7 (2021) 
Es importante entender que la verdad explicada así, puede ser interpretada como relativista o fideísta, puesto que es el individuo el que decide por uno de los términos, pero no es esto a lo que apunta nuestro autor. En nuestra lectura de sus escritos, entendemos que apunta a la necesidad de implicación del ser humano integral en la búsqueda de la verdad. Si el ser humano sólo busca con su inteligencia, sólo encontrará ideas y especulación; si sólo busca con lo emocional, sólo encontrará sentimientos ${ }^{51}$; y si sólo decide con sus propias fuerzas sin la ayuda de su Creador, será una simple decisión ética, pero nunca llegará a conocer a Dios, puesto que éste no es un elemento inmanente al mundo, al que podamos controlar con nuestra decisión: "Hay una distancia infinita, abismal, entre Dios y el hombre" 52 ; pero si busca a partir de la persona entera como existente que se compromete en su decisión haciéndola vida, a partir de su núcleo fundamental que es la conciencia, podrá encontrarse con una verdad que abarque la totalidad de su existencia y que sea una verdadera guía de ésta:

El que especula, tomará en consideración el cristianismo. Para él es indiferente que alguien lo admita o no; esas preocupaciones son propias de los seminaristas y los laicos. (...) Él toma en consideración el cristianismo para penetrarlo con su pensamiento especulativo, o sea, genuinamente especulativo. Supongamos que todo lo anterior es una quimera, que no se puede llevar a cabo en absoluto; supongamos precisamente que el cristianismo está en la subjetividad, que es interiorización. (...) Supongamos, por tanto, que la indiferencia objetiva no puede llegar a saber absolutamente nada. Sólo lo semejante conoce a lo semejante (...) cuando se trata de una observación en la que es importante que el observador se halle en un estado determinado; lo que sucede, en efecto, es que cuando no se encuentra en dicho estado, no conoce nada en absoluto ${ }^{53}$.

Para Kierkegaard la fe, cuyo salto es precedido por la incertidumbre, es lo opuesto a la duda precisamente por la existencia del salto. El conocimiento empieza por la duda porque el lenguaje marca una distancia respecto a la realidad que da cabida a ésta. Por eso en el camino hacia la verdad es necesario creer. La conciencia choca frente a la realidad e intenta aprehenderla. Para

51 En este sentido Kierkegaard alude muchas veces al pensamiento de Schleirmacher, de quien recibió mucha influencia. Está de acuerdo con él en que la pasión, el corazón es fundamental para encontrar a Dios. Sin pasión, nunca realizaríamos el salto de la fe ni llegaríamos a la unidad como personas; pero sólo la emoción nos deja en lo 'múltiple', puesto que sin la reflexión nos dejaríamos llevar por los diferentes estados de ánimo y nos quedaríamos en la cuestión estética.

52 Søren Kierkegaard, Ejercitación del cristianismo, p. 111.

53 Søren Kierkegaard, Postscriptum, p. 63. 
el pensador danés cuando hay evidencia objetiva, tenemos certeza absoluta; cuando hay probabilidad, tendremos aproximaciones; y cuando sólo hay posibilidad, el acceso acontece a través de la fe, que siempre es voluntaria; puesto que también podemos negar la posibilidad y optar por dudar.

Dudar o creer son decisiones motivadas por las pasiones: el miedo a equivocarse o la valentía de arriesgar. Estas decisiones no son ya conocimiento, ni se apoyan en la evidencia obtenida, porque de dicha evidencia no podemos obtener una conclusión objetiva:

La conclusión de la fe no es una conclusión, sino una decisión; por ello la duda está excluida. Cuando la fe concluye: 'esto existe, ergo ha devenido', podía parecer una conclusión de efecto a causa. Sin embargo, no es del todo exacto e incluso si así fuera, ha de recordarse que la conclusión del conocimiento es de causa a efecto, o mejor, de la razón a la consecuencia. (...) No es del todo exacto, porque no puedo percibir ni conocer inmediatamente que lo que percibo y conozco inmediatamente es un efecto, ya que inmediatamente sólo 'es'. Que sea un efecto lo creo, ya que para afirmar que es efecto tengo que haberlo hecho dudoso en la incertidumbre del devenir. Pero si la fe decide sobre ello, la duda se suprime: en el mismo instante el equilibrio y la indiferencia de la duda son suprimidas no por el conocimiento sino por la voluntad. (...) La fe es lo contrario de la duda. Fe y duda no son especies de conocimiento que se determinan en continuidad una con otra, ya que ninguna de ellas es un acto de conocimiento, sino que las dos son pasiones contrapuestas. La fe es sentido del devenir, y la duda es una protesta contra toda conclusión que quiere ir más allá y por encima de la percepción inmediata y del conocimiento inmediato. Quien duda no niega la existencia propia, por ejemplo, sino que no concluye nada, ya que no quiere ser engañado. Usa la dialéctica para hacer siempre a los contrarios idénticamente verosímiles, pero no establece en virtud de ella su escepticismo-, (...) sino que decide cesar y abstenerse de toda conclusión en virtud de la voluntad ${ }^{54}$.

\section{Conclusión}

Las conclusiones obtenidas sitúan el pensamiento de Kierkegaard en un volicionismo en el cual para tener fe es necesario querer. Y este querer de una subjetividad libre no es una conclusión a la evidencia objetiva alcanzada, sino un elemento independiente que se niega a dudar y que no renuncia a captar la realidad en el devenir de la existencia. Por tanto, nos plantea la necesidad de creer para poder acceder a la verdad. Esto es así si

${ }^{54}$ Søren Kierkegaard, Migajas, p. 90-91. 
compartimos la pasión por la verdad más alta que no podemos aprehender nunca en su totalidad: Dios. Sólo el verdadero amante quiere perderse para ganar al amado. Sólo donde la razón es capaz de negarse y cargar con su propio límite, puede ser capaz de trascender hasta la verdad última de la existencia, que no está en lo temporal que deviene, sino en lo eterno: "La paradoja concilia lo contradictorio, es la eternización de lo histórico y la historización de lo eterno" 55 .

En la fe religiosa, por tanto, podremos legítimamente decidir creer. Legítimamente desde el punto de vista psicológico, puesto que somos libres y por ello capaces de elegir entre creer o dudar; y legítimamente desde el punto de vista lógico, puesto que es el propio dinamismo del Espíritu el que nos lleva hasta nuestros límites racionales en la búsqueda de la verdad y capta la posibilidad de aceptar lo que la trasciende. Querer y creer, por tanto, se necesitan mutuamente en lo que a la fe religiosa se refiere. Este salto no es irracional, puesto que la razón no alcanza a darse a sí misma el encuentro con Dios. Es un fenómeno existencial en cuya participación se requieren dos: Dios como ser personal, que se hace presente como y cuando quiere, y el ser humano como espíritu libre, que puede decidir responderle confiadamente en su Presencia.

\section{Bibliografía}

\section{Obras de Kierkegaard}

Kierkegaard, Søren, Migajas filosóficas o un poco de filosofía, trad. de Rafael Larrañeta, Madrid: Trotta, 2007.

— Postscriptum no científico y definitivo a 'Migajas filosóficas', trad. de Javier Teira y Nekane Legarreta, Salamanca: Sígueme, 2010.

_ O lo uno o lo otro, trad. de Begonia Saez Tajafuerte y Darío González, Madrid: Trotta, 2007.

- Ejercitación del cristianismo, trad. de Demetrio G. Rivero, Madrid: Guadarrama, 1961.

L Los lirios del campo y las aves del cielo, trad. de Demetrio G. Rivero, Madrid: Guadarrama, 1963.

El concepto de la angustia, trad. de Darío González y Oscar Parcero, Madrid: Trotta, 2016.

55 Ibíd., p.73. 


\section{Otras obras consultadas}

Buber, Martin, Dos modos de fe, trad. de Ricardo de Luis Carballada, Madrid: Caparrós, 1996.

De Aquino, Tomás, Suma teológica, Madrid: BAC, 2001.

Dobre, Catalina Elena, Pascal, Kierkegaard, Buber. Un nuevo modo de filosofar: la relación como fundamento de la existencia, Colección Persona, Madrid: Fundación Enmanuel Mounier, 2013.

Evans, C. S., Kierkegaard's 'Fragments' and Postscript', Humanities Press: Nueva York, 1983.

Herrera Guevara, Asunción, 'Teorema', vol.XXII/3, 2003.

Larrañeta, Rafael, 'Razón y Religión en Kierkegaard', Contrastes. Revista internacional de filosofía, vol. III, Málaga, 1998.

Pojman, Louis P., Religious belief and the will, Londres y Nueva York: Roulade \& Kegan Paul, 1986.

Rey de Castro, José, 'Angustia, libertad y pecado en 'El concepto de angustia' de Vigilius Haufniensis de Søren Kierkegaard', v. 10, n. 1, p. 147-165, Universidade Católica de Petrópolis, Petrópolis, 2018.

Taylor, M., Kierkegaard's Pseudonymous Authorship, Princeton University Press: Princeton, 1973. 